\section{MS33-04 Expanding the horizons of sky blue nitrosocarboranes}

Georgina M. Rosair ${ }^{1}$, Samuel L. Powley ${ }^{1}$, Louise Schaefer ${ }^{1}$, Wing Y. Man ${ }^{1}$, David Ellis ${ }^{1}$, Alan J. Welch ${ }^{1}$

1. Institute of Chemical Sciences, Heriot Watt University, Edinburgh, UK

email: G.M.Rosair@hw.ac.uk

Nitrosocarboranes are a beautiful sky blue colour in contrast to most other carborane derivatives which are colourless. However it is the ability of NO to act as both a one electron and three electron donor that inspires our use of this substituent. Since the number of polyhedral skeletal electron pairs has a key role in the structure of carboranes, NO with its one and three electron donor possibilities has potential to effect changes in carborane structure and chemistry. In this work [1] both mono and bis(carborane) nitroso species have been studied (see example below left). In all cases the nitroso group bonds to the carborane as a one electron substituent $(\mathrm{C}-\mathrm{N}-\mathrm{O}$ angle ca. 113 degrees). An unexpected challenge arose in that two of the species (e.g. Fig. 1 left ) are liquid at room temperature so structure determinations were performed on crystals grown in situ on the diffractometer from liquid samples. Glass Lindemann $0.3 \mathrm{~mm}$ capillaries are the only additional equipment required for a standard data collection (in addition to patience and manual dexterity).

Both mono- and dinitroso derivatives of meta carborane and 1, $1^{\prime}$-bis $(m$-carborane $)$ were synthesised and structurally characterised. However the mononitroso derivative of bis( $o$-carborane) could not be prepared by the same method, instead the colourless hydroxylamine derivative was formed. Reasons behind this were explored and identified. The dinitroso ortho-carborane and bis( $o$-carborane) species were also elusive with alternative products proposed . Another strategy was employed for these ortho compounds; since the NO group can undergo Diels-Alder cycloaddition reactions with a cyclic 1,3-diene, we prepared derivatives of the unobtainable dinitroso ortho-carborane and bis $(o$-carborane) (Fig. 1, right)

1. S. L. Powley, L. Schaefer, W. Y. Man, D. Ellis, G. M. Rosair and A. J. Welch, Dalton Trans., 2016, 45, 3635 .
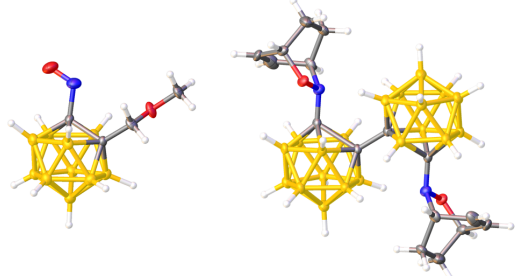

Figure 1. [1-NO-2- $\mathrm{CH}_{2} \mathrm{OCH}_{3}-1,2$-closo- $\left.\mathrm{C}_{2} \mathrm{~B}_{10} \mathrm{H}_{10}\right]$ left and isolated derivative of dinitroso bis( $o$-carborane) (right).
MS33-O5 Silolyl-FeCp complexes: is there a way to sila-ferrocene?

Petra Bombicz ${ }^{1}$, Csaba Fekete ${ }^{2}$, Réka Mokrai² ${ }^{2}$ László Nyulászi² Ilona Kovács ${ }^{2}$

1. Institute of Organic Chemistry, Research Centre for Natural Sciences, Hungarian Academy of Sciences, Magyar Tudósok körútja 2, Budapest, H-1117, Hungary

2. Department of Inorganic and Analytical Chemistry, Budapest University of Technology and Economics, Szt. Gellért tér 4, Budapest, H-1111, Hungary

\section{email: bombicz.petra@ttk.mta.hu}

One of the milestones in organometallic chemistry is the synthesis of ferrocene by Kealy and Pauson in 1951 $[1,2]$ and the determination of its structure by Wilkinson and Woodward in 1952 [3]. These achievements opened up the way to the use of metallocenes in applied and material science from polymerization catalysis to UV fluorescent materials [2]. Nowadays several metallocenes are known in which not just the central iron atom is replaced by other transition metals but also the ligands are changed to heterocyclopentadienyl analogues containing other main group elements such as $\mathrm{P}, \mathrm{As}$ or $\mathrm{Sb}$ $[4,5]$. Notwithstanding, the number of known metallocenes possessing silicon or germanium containing heterocycles is small.

The reaction of 1-chlorosilols and $\mathrm{K}\left[\mathrm{Fe}(\mathrm{CO})_{2} \mathrm{Cp}\right]$ in THF yielded two new $\eta^{1}$-silolyl-FeCp(CO $)_{2}$ complexes in good yield. We report the molecular and crystal structures of the complexes, and their attempted transformation (by heating or UV irradiation) to the metallocenes. The reason for the increased stability of these carbonyl complexes can be attributed to the increased $\sigma$-electron donating behaviour of the silicon to the central $\mathrm{Fe}$, while the aromaticity of the silolyl ligand seems to have less influence [6].

References:

[1] Kealy, T. J.; Pauson, P. L. "A New Type of Organo-Iron Compound". Nature 168(4285): 1039-1040. 1951.

[2] Pauson, P. L. "Ferrocene-how it all began". J. Organomet. Chem. 637-639: 3-6. 2001.

[3] G. Wilkinson, M. Rosenblum, M. C. Whiting, R. B. Woodward. "The Structure of Iron Bis-Cyclopentadienyl". Journal of the American Chemical Society 74(8): 2125-2126. 1952.

[4] R.S.P. Turbervill, A.R. Jupp, P.S.B. McCullough, D. Ergöcmen, J.M. Goicoechea. "Synthesis and Characterization of Free and Coordinated 1,2,3-Tripnictolide Anions" Organometallics 32. 2234-2244. 2013.

[5] M. Fleischmann, S. Welsch, H. Krauss, M Schmidt, M. Bodensteiner, E.V. Peresypkina, M. Sierka, C. Gröger, M. Scheer, "Complexes of Monocationic Group 13 Elements with Pentaphospha- and Pentaarsaferrocene" Chem. Eur. J. 20 3759-3768. 2014.

[6] C. Fekete, R. Mokrai, P.Bombicz, L. Nyulászi, I. Kovács:,$\eta^{1}$-silolyl-FeCp(CO) ${ }_{2}$ complexes. Is there a way to sila-ferrocene?" Journal of Organometallic Chemistry 799-800. 291-298. 2015.

Keywords: sila-ferrocene, silolyl-FeCp complexes

Keywords: Nitroso, carborane, in-situ crystallography 